\section{References}

LANGER, J., \& ROSENBERG, B. G. Non-verbal representation of verbal referents. Percept.mot.Skills, 1964, 19, 663-670.

NOBLE, C. E. Measurement of association value (a), rated association $\left(a^{\prime}\right)$, and scaled meaningfulness $\left(\mathrm{m}^{\prime}\right)$ for the $2100 \mathrm{CVC}$ combinations of the English alphabet. Psychol. Rep., 1961, 8, 487-521.

ROSENBERG, B. G., \& LANGER, J. A study of posturalgestural communication. Submitted to J.Pers., 1964.
WERNER, H., \& KAPLAN, B. Symbol formation. New York: Wiley, 1963.

\section{Notes}

1. This investigation was supported by grant MH 0799401 from the National Institute of Mental Health.

2. The authors are indebted to Mr. Raymond White and Miss Judith Griffiths for their assistance in the present study.

\title{
A methodological note on the Palmar Sweat Index (PSI)
}

\section{Gordon L. Paul UNIVERSITY OF ILUNOIS}

\begin{abstract}
Commercial PSI apparatus was found to be convenient and practical; however, requiring clarification of methodology: (a) Change scores based on the same finger appear to be the only meaningful data; (b) Re-calibration of the densitometer is necessary with each print; (c) Dial readings should be made only after complete stabilization of the indicator, and; (d) all readings should be taken at the same time from printing, preferably 28 days or more.

The PSI, developed by Kuno (1956), used by Mowrer (1953) and colleagues, Haywood \& Hunt (1963) and students, and others (see Winter et al., 1963), has become a more standardized and practical photometric measure of "emotional" perspiration due to the introduction of commercial apparatus. Film and printer (\#6000) of Lab-Line Instruments, Inc., Chicago, makes possible the obtainment of "instantaneous" records of palmar sweat in approximately 90 seconds with no discomfort to Ss. Only 30 seconds drying time is required after painting the volar surface of S's finger with solution (3 drops of hydrochloric acid added to $13 \mathrm{~g}$ anhydrous ferric chloride in 400 cc chemically pure acetone) before insertion into the printer, which presses the film against S's finger for 30 seconds with a constant pressure of 1 pound, yielding a "permanent" record of sweat production. Lab-Line densitometer $(\# 6010)$ then provides direct PSI dial readings, corresponding to the density of a print, through comparison of the amount of light allowed through a set area at the center of a print with that of clear film via photoelectric cells.
\end{abstract}

During the course of a recent investigation of outcome effects of psychotherapy, to be published elsewhere, ${ }^{2}$ in which the above apparatus was provided by Dr.J. McV. Hunt, and Lab-Line Instruments Inc., several methodological points became evident, in addition to those previously mentioned in the literature. (a) Since densitometer readings are based on the amount of light let through the print, not only amount of sweat influences the absolute level of PSI, but also, distance between print swirls. Therefore, change s cores based on the $\mathrm{s}$ a $\mathrm{me}$ finger appear to be the only meaningful data, un-

Table 1. Mean PSI Readings Over Time

\section{Time From Printing}

1 day

1 week

3 weeks

4 weeks

Mean 13.3

$$
16.3
$$

17.6

SD $\quad 16.45$

13.49

14.48

14.72 less a means of partialling out swirl size is included. (b) A number of factors necessitate re-calibration of the densitometer before and after each reading to insure comparability, in addition to allowing a 20 minute "warmup" period. (c) Dial readings should be taken only after the needle has stabilized to the degree that extraneous noises and jars do not cause "drift" (approximately 45 minutes). (d) Most important, prints continue to darken over time from printing. A trend analysis performed on PSI readings taken from the same prints of 40 unselected S's at 1 day, 1 week, 3 weeks, and 4 weeks from printing found a highly significant effect for time (F, 101.14; df, 3/117; $p<.001)$. Means presented in Table 1 demonstrate a significant increase in readings from 1 day through 3 weeks (linear component F, 249.62; df, 1/117; p <.001), with leveling from 3 to 4 weeks (quadradic component F, 50.49; df, $1 / 117 ; \mathrm{p}<.001)$. The average $\mathrm{r}$ between any pair of reading times $(r=.992)$ indicates a highly consistent increase across all PSI levels. Therefore, lest group differences be introduced after-the-fact by E error, all PSI readings should be taken at the same point in time from printing, preferably 28 days or more.

\section{References}

HAYWOOD, H. C., \& HUNT, J. Mc. V. Effects of epinephrine upon novelty preference and arousal. J.abn. soc. Psychol., 1963, 67, 206-213.

KUNO, Y. Human perspiration. Springfield, Ill.: Thomas, 1956.

MOWRER, O. H. (Ed.) Psychotherapy: Theory and research. New York: Ronald, 1953.

WINTER, W. A., FERREIRA, A. J., \& RANSOM, R. Two measures of anxiety: A validation. J. consult. Psychol., $1963,6,520-524$.

\section{Note}

1. This research was partially supported by Public Health Service Fellowship No. 1 F1 MH-19, 873-01 from the National Institute of Mental Health, Public Health Service.

2. Paul, G. L. Effect of insight, desensitization and attention-placebo treatment of anxiety: An approach to outcome research in psychotherapy. 